\title{
Fetal and Neonatal Ductus Arteriosus Is Regulated with ATP-Sensitive Potassium Channel
}

\author{
Kazuo Momma, Mika Monma, Katsuaki Toyoshima, Emiko Hayama, \\ and Toshio Nakanishi
}

\section{Keywords}

Ductus arteriosus • Fetus • ATP-sensitive potassium channel • Sulfonylurea • Potassium channel opener

The fetal patency and neonatal closure of the ductus arteriosus (DA) are regulated with oxygen and prostaglandins. The proposed oxygen sensors of fetal and neonatal DA include P450-endothelin and the Kv channel [1]. We hypothesized that the ATP-sensitive potassium channel ( $\mathrm{K}_{\mathrm{ATP}}$ channel) is another oxygen sensor [2].

Fetal and neonatal DA was studied with Wistar rats; sulfonylurea drugs including tolbutamide, chlorpropamide, gliclazide, glimepiride, and glibenclamide $\left(\mathrm{K}_{\mathrm{ATP}}\right.$ channel inhibitors); diazoxide and pinacidil ( $\mathrm{K}_{\mathrm{ATP}}$ channel openers, KCOs); and rapid whole-body freezing (Fig. 37.1).

Tolbutamide, chlorpropamide, and gliclazide easily passed across the placenta and constricted fetal DA dose-dependently following orogastric administration to near-term pregnant rats. The fetal DA constricted $30 \%$ with clinical doses of sulfonylurea drugs and closed completely with larger doses.

Glimepiride and glibenclamide passed across the placenta minimally and only mildly constricted the fetal DA after maternal administration, but constricted and

K. Momma $(\bowtie) \cdot$ E. Hayama • T. Nakanishi

Department of Pediatric Cardiology, Tokyo Women's Medical University, Kawadacho 8-1,

Shinjyuku-ku, Tokyo 162-8666, Japan

e-mail: kmomma@iris.ocn.ne.jp

\section{Monma}

Department of Obstetrics and Gynecology, Shounan-Kamakura General Hospital, Okamoto 1370-

1, Kamakura 247-8533, Japan

K. Toyoshima

Department of Neonatology, Kanagawa Children's Medical Center, Mutukawa 2-138-4

Minamiku, Yokohama 232-8555, Japan

T. Nakanishi et al. (eds.), Etiology and Morphogenesis of Congenital Heart Disease,

DOI 10.1007/978-4-431-54628-3_37 


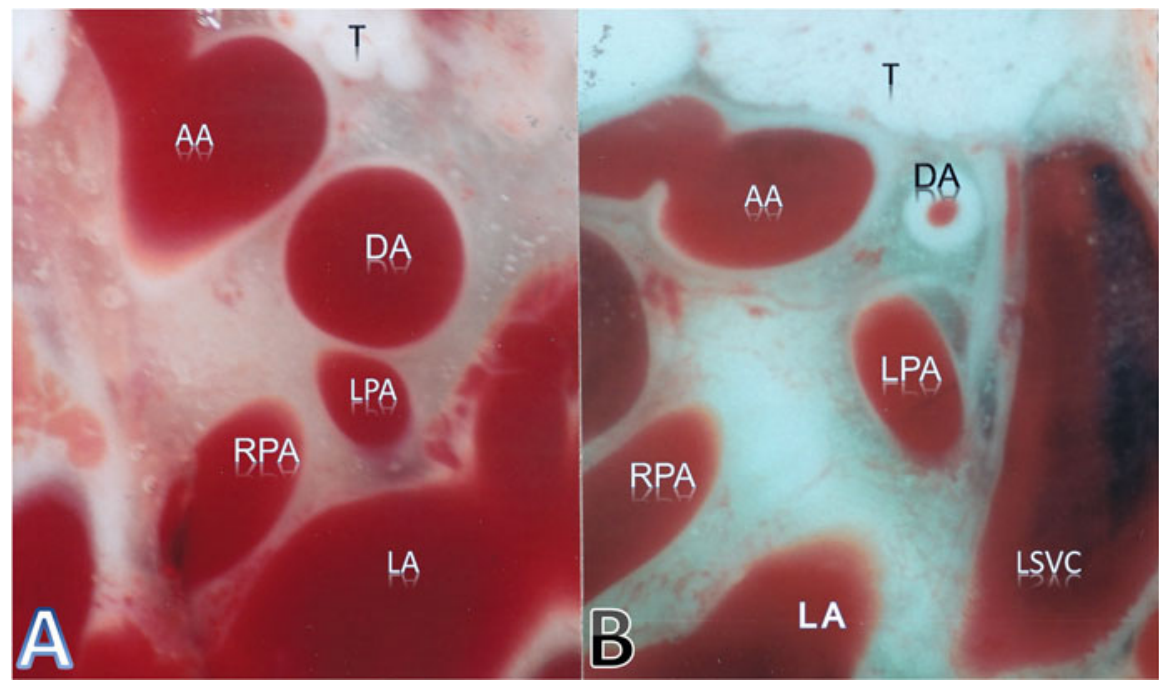

Fig. 37.1 The fetal ductus arteriosus was studied in the near-term fetus or newborn rat following rapid whole-body freezing, cutting on the freezing microtome, with a microscope and a micrometer. The control fetus shows a widely open ductus (a), and the fetus with glibenclamide $(10 \mathrm{mg} / \mathrm{kg}$; 10-100 times clinical dose injected at $1 \mathrm{~h}$ before) shows severely constricted ductus (b). $A A$ aortic arch, $D A$ ductus arteriosus, $L A$ left atrium, $L P A$ left pulmonary artery, $L S V C$ left superior vena cava, $R P A$ right pulmonary artery, $T$ thymus

closed the fetal DA dose-dependently with direct fetal injection. Fetal DA closure was associated with hydrops and fetal death.

Diazoxide and pinacidil delayed DA closure following neonatal injection immediately postnatally and dilated the closing DA with injection at $60 \mathrm{~min}$ postnatally.

All tested sulfonylurea drugs constricted fetal DA dose-dependently and with complete closure at large doses. KCOs dilated the neonatal DA. These results indicate physiological regulation of fetal and neonatal DA with $\mathrm{K}_{\mathrm{ATP}}$ channels.

This study has several clinical implications. Sulfonylurea-associated fetal death was first reported 50 years ago. The mechanism of death remained unclear prior to this study. Sulfonylureas may be useful for closing patent DA in premature neonates.

Recently reported neonatal DA reopening associated with the use of diazoxide for hyperinsulinemic hypoglycemia has been proved experimentally. DA-dilating effect of KCO drugs may be useful as a bridge to surgery in neonatal DA-dependent congenital heart diseases.

Open Access This chapter is distributed under the terms of the Creative Commons AttributionNoncommercial 2.5 License (http://creativecommons.org/licenses/by-nc/2.5/) which permits any noncommercial use, distribution, and reproduction in any medium, provided the original author(s) and source are credited.

The images or other third party material in this chapter are included in the work's Creative Commons license, unless indicated otherwise in the credit line; if such material is not included in 
the work's Creative Commons license and the respective action is not permitted by statutory regulation, users will need to obtain permission from the license holder to duplicate, adapt or reproduce the material.

\section{References}

1. Coceani F, Baragatti B. Mechanisms for ductus arteriosus closure. Semin Perinatol. 2012;36:92-7.

2. Nakanishi T, Gu H, Momma K, et al. Mechanisms of oxygen-induced contraction of ductus arteriosus isolated from the fetal rabbit. Circ Res. 1993;72:1218-23. 